\title{
AN EVALUATION OF MECHANICAL CHARACTERISTICS OF AN ELECTRIC MOTORCYCLE WITH A DRIVE SYSTEM INTEGRATED A CVT TRANSMISSION
}

\author{
TUAN-ANH BUI ${ }^{1}$, VAN-HUNG PHAM ${ }^{1}$, MANH-TOAN NGUYEN ${ }^{1 *}$, THUY-DUONG NGUYEN ${ }^{*}$ \\ \& NGOC-TAM BUI ${ }^{1,2 *}$
}

${ }^{1}$ School of Mechanical Engineering, Hanoi University of Science and Technology, Hanoi, Vietnam

${ }^{2}$ College of Systems Engineering and Science, Shibaura Institute of Technology, Tokyo, Japan

\begin{abstract}
Electric motorcycles are widely used in developing countries due to the typical advantages of electric vehicles such as not using gasoline, saving operating costs, etc. Especially, the use of electric power sources will contribute to the environmental protection due to pollution of exhaust emission from vehicles using gasoline fuel. This is a sustainable development direction for modern transport and is interested by many countries around the world. However, most types of electric motorcycles do not integrate a CVT transmission into the drive system, thus, it does not ensure a suitable torque at low speeds, especially when travelling in the special traffic conditions in urban areas. This paper presents a design of a drive system including a CVT transmission integrated into a Cygnus motorcycle frame to develop an electric motorcycle with the goal of safe operation, avoiding the phenomenon of sliding and jerking when the speed changes. The results show that the motorcycle operates stably with design parameters with the capable of operating at the maximum torque of 44.14 N.m at wheel speed of $173 \mathrm{rpm}$. At other speed ranges, the system automatically adjusts CVT ratios corresponding to those speeds, so that the wheel shaft torque will be suitable for the corresponding operating conditions, ensuring vehicle performance, avoiding slipping and jerking phenomenon when changing state from low speed to high speed.
\end{abstract}

KEYWORDS: CVT Transmission; Electric Motorcycle; Wheel Shaft Speed \& Wheel Shaft Torque

Received: Jun 09, 2020; Accepted: Jun 29, 2020; Published: Aug 07, 2020; Paper Id.: IJMPERDJUN2020684

\section{INTRODUCTION}

Electric motorcycles and electric bicycles are used more and more widely due to their convenience and certain advantages for gasoline-powered vehicles. Using electricity will contribute to solving the problem of environmental pollution for means of transport. In Vietnam, Electric motorcycles have become a popular transport for students, seniors, and office workers. However, the characteristics of urban traffic, road users need to stop or move every time they encounter traffic signals or go uphill or downhill when participating in overpasses or ramp sections, so they must change the speed when passing through crowded areas such as school gates, markets, etc. On the other hand, most electric motorcycles in Vietnam do not include a stepless drive part, thus, the motor is directly attached to the executive unit, causing for difficult control of traffic transports in the above-mentioned cases. The characteristics of electric vehicles when the starting torque is small and will not have the relative slippage of friction as motorcycles. Therefore, it is necessary to improve the efficiency of use or increase the safety of people and equipment when participating in traffic.

Due to the need to use clean energy for private vehicles, especially in developing countries, scientists have researched and applied electric motors to electric motorbikes or bicycles. Based on scientific and technological 
achievements, the research results are increasingly applicable, and the efficiency of using electric motors is higher and safer. Y. Liu et al. said that electric motorcycles can help to reduce carbon emissions for the sustainable development of the environment. Basing on the perceptions of environmental policy, pollution reduction, etc. the motorcyclists can accept electric motorbikes as an alternative [1]. P. Jeyapandiarajan et al. showed a simulation of a chassis analysis for an electric motorcycle to find the most suitable material basing on strength, cost and weight of the chassis [2]. In aspect of traffic noise and emissions, M. Hernandez et al. showed the environmental benefits when using electric motorcycles in comparison with gasoline-powered motorcycles [3]. M. Marinov et al. proposed a methodology to develop electric motorcycles with different capacities and for different driving conditions. The authors confirmed in a study on the electrical sizing of the electric motorcycle drive that when driving on a flat surface in urban conditions at a constant speed, a rated motor power about $35 \%$ is used [4].

When converting an internal combustion engine motorcycle into a battery-powered electric one, the life cycle energy consumed and emissions reduced $72 \%$ and $45 \%$, respectively. This is significant considerations for the current global issue of transportation [5]. In 2012, David G. Dorrell from Sydney University of Technology and Mircea Popescu from Motor Design Ltd, Elsmere, UK presented the study of electric motor for electric motor. The authors presented a design solution for electric motorcycles based on the use of brushless permanent magnet electric motors (DC or AC) with a wide range of speed and power. The motor can operate at high current density and accelerate in a short time [6]. In 2016, Siriporn Ruensumruay et al. presented a study of the influence of electric motorcycles on energy consumption in Thailand. The authors proposed an electric motorcycle model using the Artificial Neuro-Fuzzy Inference Systems (ANFIS). The physical and technical information of motorcycles was collected from survey questionnaires in Bangkok and urban areas. The authors proposed that the important factors that affect the energy consumption of a motorbike are motor size (cc.), longevity (years), distance $(\mathrm{km} /$ day), average speed $(\mathrm{km} / \mathrm{h})$. Energy consumption in the transport sector is modeled on several scenarios for the number of electric motorcycles in the future. The authors suggested that this development model can forecast energy consumption in preparation for future transport energy planning [7]. In 2012, Daigo Tokunaga and Katsumi Kesamaru presented a development of a new PM motor for sport electric motorcycles. The authors proposed that the requirement for electric motorbikes is high-performance motors operating at variable speeds. A permanent magnet motor can be operated at rated power with high efficiency but low efficiency at high speeds. Therefore, the authors presented new techniques to improve the efficiency and proposed motor specification for electric motorcycles [8]. An analysis and comparison of control techniques in electric motor drive systems were given by E. Fernandez and M. Coello proposed [9]. The authors presented the simulation of two control techniques for an electric motor drive system. The proposed control modes are field oriented control (FOC) and direct torque control (DTC). The analysis involves a comparison between two types of controls and analyzing the advantages and disadvantages of each technique. The purpose is to validate the best technology that is more efficient, easy to implement and most cost effective to carry out in the future on a prototype electric motorcycle. The article contributes to the movement of electric vehicles for students in Cuenca Ecuador, addressing environmental pollution reduction and traffic saturation [10].

Electrical system is one of the most important unit in an electric motorcycle which determines the capacity, travelling distance of the vehicle. A design of electrical system for racing electric motorcycles has been proposed by J. Blissett et al. with purpose of maximizing the vehicle performance in race conditions [11], [12]. S. Matey e al. presented a design and fabrication of a e-bike with power source from battery and it can be upgraded to use solar energy from solar panels [13]. To improve the travelling distance of an electric motorcycle, T. Phan et al. proposed two additional charging 

with a Drive System Integrated a CVT Transmission

methods by using solar panel and braking system for a commercially electric motorcycle [14]. Solar energy will become a potential power source for electric motorcycles or other electric vehicles [15], [16], [17], [18]. F. Ibanez at al. presented a study on extending the autonomy of a battery for electric motorcycles by adding a supercapacitor bank to a lithium-ion battery pack. The authors said that the battery capacity is extended up to $7.8 \%$ but an extension of the net capacity of the whole system is only $3.7 \%$ due to the losses from the converter [19]. Electric motor parts are not always suitable for electric motorcycles, designers need to design some parts to fit the existing chassis but with the right structure and minimize weight as possible [20]. These motorcycles do not yet have CVT stepless drives, the motor is directly attached to the actuator, making it difficult to control, having a small starting torque, and no relative slippage as using a friction clutch of motorcycle. Therefore, the efficiency of using electric motors on electric motorbikes with a solution to improve mechanical properties based on integrating a CVT transmission into a motorbike drive system is presented.

\section{EXPERIMENTAL PROCEDURE}

\subsection{Drive System Integrated a CVT Transmission}

Starting from the requirement of integrating electric motor and CVT transmission into an old motorbike frame, the drive system diagram is described as Figure 1.

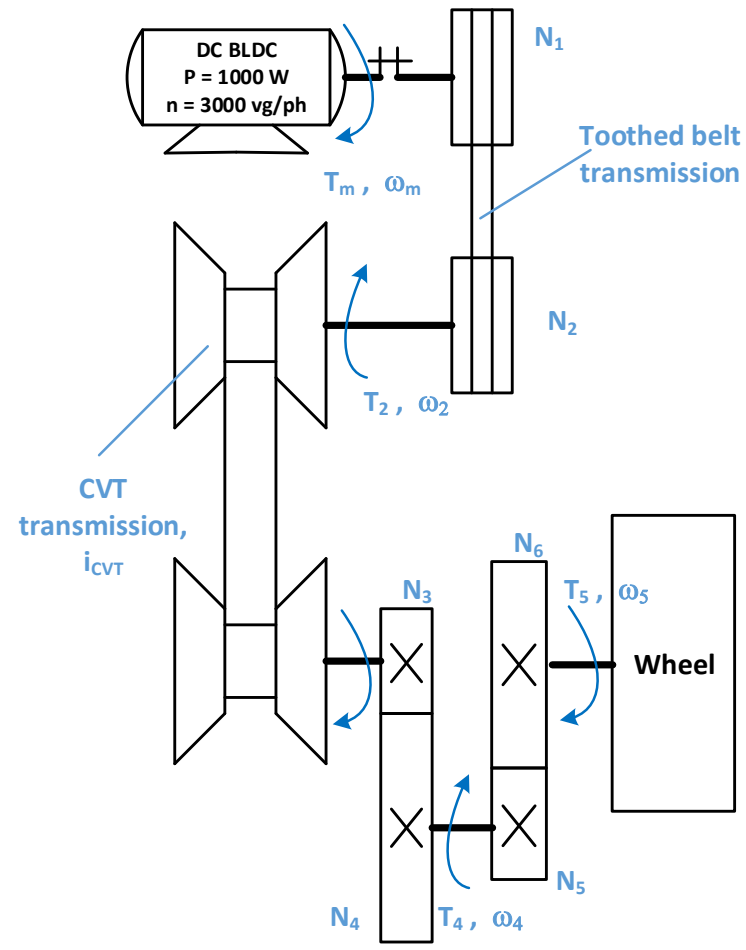

Figure 1: Dynamic Diagram of the Drive System using CVT Transmission.

The CVT transmission is designed based on the motor housing and drive shaft of the Cygnus motorcycle. Replacing damaged or unreasonable parts, rearranging transmissions reasonably so that CVT transmission can be installed on the existing motorbike frame.

The DC electric motor selected is a BLDC motor with a power of $1000 \mathrm{~W}$, the speed of motor shaft of $3000 \mathrm{rpm}$, using a $48 \mathrm{~V}$ power source. Therefore, the electric power supplying for the motor is designed including four batteries of $12 \mathrm{~V}, 20 \mathrm{Ah}$ connected in series. The vehicle travel time with maximum motor power is calculated as $\mathrm{T}=1.92$ hours for 
each single charge. On the other hand, the ratio of the CVT transmission is designed to vary in a range of $0.5-2$, while the existed gear transmissions with a total ratio of 1: 7.8 is located in front of the wheel axle (as shown in figure 1). So, the maximum wheel speed is determined as follows:

$$
V_{\max }=\frac{n \times \pi D}{7.8 \times 60 \times 10^{3}}
$$

The output shaft of the motor is fitted with a toothed drive belt, which is selected to fit with the existing motorcycle body frame, the basic parameters of the drive system are described in table 1.

Table 1: Basic Parameters of the Drive System

\begin{tabular}{|l|c|}
\hline \multicolumn{1}{|c|}{ Specification } & Value \\
\hline Number of teeth of toothed pulley, $\mathrm{N}_{1}=\mathrm{N}_{2}$ & 60 \\
\hline Teeth pitch of pulley and belt, $\mathrm{p}_{1}=\mathrm{p}_{2}(\mathrm{~mm})$ & 5.08 \\
\hline Pulley diameter, $\mathrm{d}_{1}=\mathrm{d}_{2}(\mathrm{~mm})$ & 97 \\
\hline CVT transmission ratio & $0.5-2$ \\
\hline Ratio of gear transmissions $\left(\mathrm{N}_{3} / \mathrm{N}_{4}\right) .\left(\mathrm{N}_{5} / \mathrm{N}_{6}\right)$ & $1 / 7.8$ \\
\hline
\end{tabular}

With the parameters selected to match the existing motorcycle body structure, the CVT transmitter needs to design to be able to create a continuous range of ratios within the designed range. Thus, the force system will take care of moving the mobile pulley part in the CVT transmission. When the CVT transmission reaches the largest ratio, the active and passive pulley parts diameters are $28 \mathrm{~mm}$ and $84 \mathrm{~mm}$, respectively, the belt velocity is then $13.2 \mathrm{~m} / \mathrm{s}$, which corresponds to the maximum motor speed of $3000 \mathrm{rpm}$. The force exerted on the sliding pulley part is calculated by 61.18 N. The control system was designed, manufactured, and tested the working status of the system in case of traffic. The tests were carried out to assess the stability of the system before being integrated into electric motorcycles. It shows that the designed and manufactured parts are suitable for integrating the CVT transmission into the Cygnus motorcycle body frame, promising a stable system with design parameters.

The drive system integrates a CVT transmission system which has been designed, manufactured, and installed in the body frame of the motorcycle, replacing the drive system using the petrol engine of the vehicle. A BLDC motor is installed with a few parts that have been designed and fabricated to fit the Cygnus body frame. The main components of the motorcycle's drive system, including a belt-pulley transmission, a CVT transmission, etc., have been designed, fabricated, and assembled into the body frame as described in figure 2.

The electric system was installed with fire safety requirements. The control system was installed and connected with carefully controlled parts of the motorcycle. After installing the new driving, electrical and control systems, the electric motorbike was formed, and it was necessary to test its performance. After installation, the tests were conducted to find out the most appropriate set of control parameters for electric motorbikes in urban Vietnam.

The results show that electric motorbikes operate stably with the speeds changing from 0 to approximately 30 $\mathrm{km} / \mathrm{h}$. The maximum operating time for each single charge is about $1.9 \mathrm{~h}$ in accordance with a travelling distance of $57 \mathrm{~km}$. This result is obtained with tests on flat sections and does not have to stop much at intersections. This achievement may be due the speed of electric motorcycle is kept stable, reducing losses due to uphill or frequently turning on/off the motor of 
motorcycle at intersections where motorbikes must stop. These moving conditions are suitable for electric motorcycles to achieve the highest performance, longer driving time, longer travel distances. These parameters are relatively in accordance with the design requirements. These parameters are like those of electric motorcycles on the commercial market.

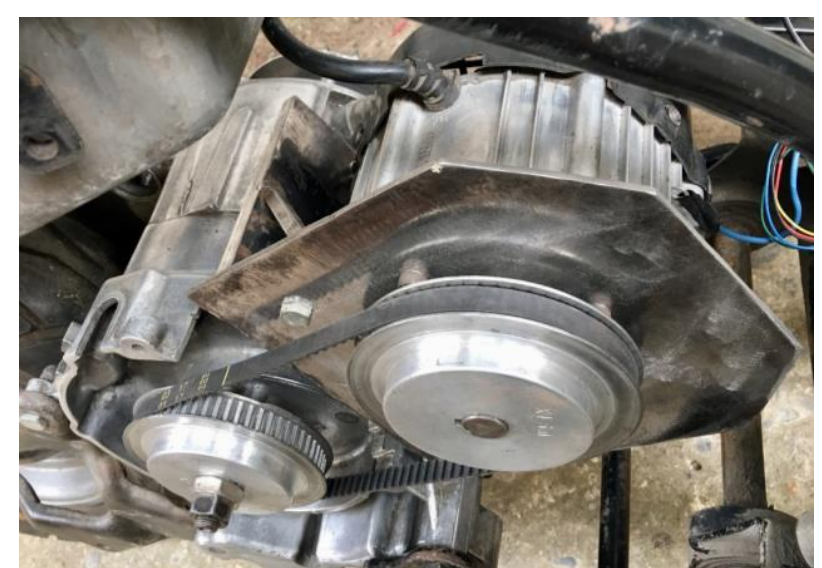

(a)

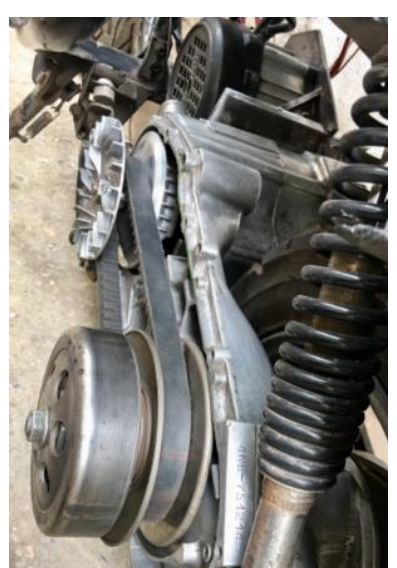

(b)

Figure 2: (a) Cygnus Body Frame with an Electric Motor; (b) Drive System Integrated with CVT Transmission.

The tests to assess jerkiness when speeding and decelerating vehicles with actual traffic conditions, especially in intersections and crowded places, have also been performed in Hanoi, Vietnam. The phenomenon of sliding, jerking when accelerating from the state of stopping is no longer happening. Indeed, the acceleration or deceleration is very gradual and gradually creates a sense of safe driving. However, the travelling distance on each single charge is usually shorter than the tests on long, flat roads and fewer intersections. The distance achieved in these tests is approximately $51 \mathrm{~km}$. This may be the losses due to the speed changes on uneven road sections, sections passing through crowded places, uphill or downhill roads, or roads with multiple intersections causing vehicles must stop temporarily. As such, it has satisfied the purpose of integrating a CVT transmission to the drive system to improve the safety of using electric motorcycles in specific urban traffic.

One of the most important mechanical properties of a vehicle is its wheel torque. The relationship between the torque and speed of the motorcycle will be used to evaluate a design criterion for the ability to operate in urban traffic conditions when the speed needs to be regularly changed. In this study, this relationship will be analyzed to assess the appropriateness of the design and integration of a drive system containing a CVT transmission into the Cygnus body frame.

Basing on the dynamic diagram of the electric motor drive system shown in Figure 1, the torque of the motor output shaft can be described as follows [21]:

$$
T_{m}=-\frac{K_{b} \cdot K_{t}}{R_{a}} \omega_{m}+\frac{K_{t}}{R_{a}} e_{a}
$$

Where, $\mathrm{e}_{\mathrm{a}}$ - armature voltage of the motor; $\mathrm{K}_{\mathrm{b}}, \mathrm{K}_{\mathrm{t}}$, and $\mathrm{R}_{\mathrm{a}}$ are the electric motor constants.

Assuming ignoring losses between the transmissions, the wheel shaft torque can be determined by an expression as follows: 
$T_{4}=\frac{N_{2}}{N_{1}} \cdot \frac{N_{4}}{N_{3}} \cdot \frac{N_{6}}{N_{5}} \frac{1}{i_{C V T}} \cdot T_{m}$

Where, $\mathrm{i}_{\mathrm{CVT}}$ - CVT transmission ratio.

With motor parameters and transmissions designed, Eq. (5) can be rewritten as follows:

$$
T_{5}=-\frac{7.8}{i_{C V T}}\left(\frac{1}{10 \pi^{2}} \omega_{m}-\frac{10}{\pi}\right)
$$

The DC electric motor used for the drive system has a maximum torque about $3.2 \mathrm{Nm}$ and the maximum rotation speed of $3000 \mathrm{rpm}$.

\subsection{Experiment Setup}

In order to evaluate the mechanical properties of the electric motorcycle after integrating the drive system with a CVT transmission, it is necessary to determine the wheel shaft torque change according to its speed. Thus, a measurement of torque was designed and fabricated for this purpose. The measuring system consists of the main components such as a lever, belts, suspension frames, bearings, barrel, electronic scale, elastic coupling, counterbalance, which was designed based on the principle diagram described as shown in figure 3.

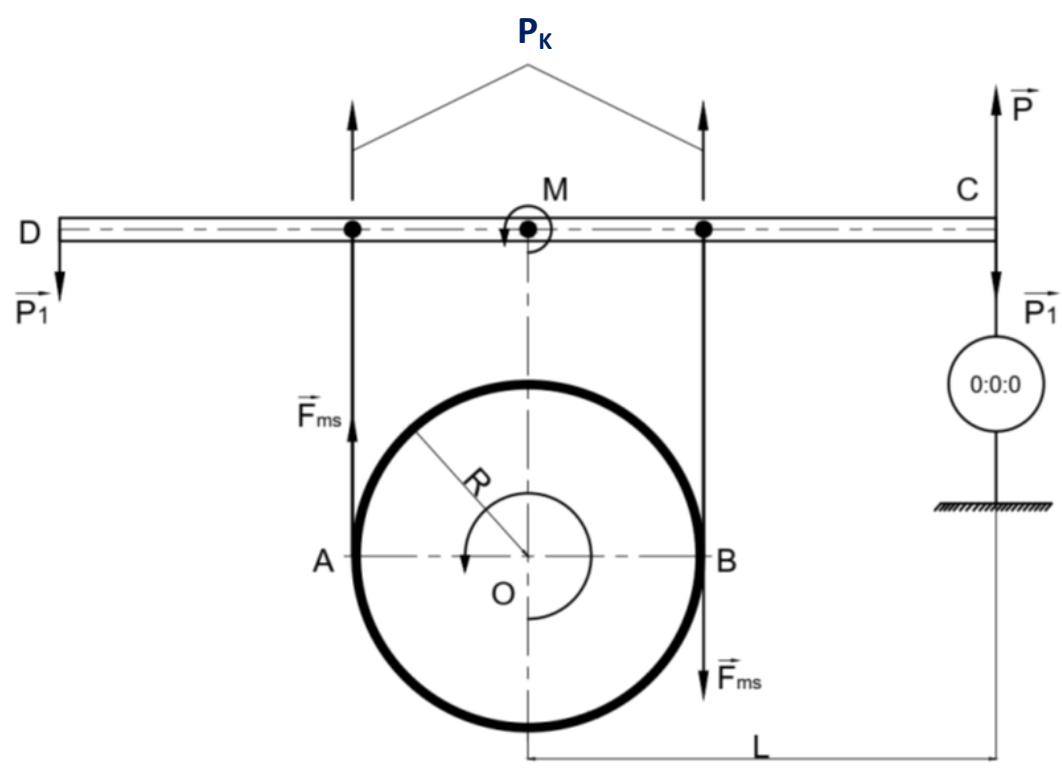

Figure 3: Principle Diagram of a Measurement System of Wheel Shaft Torque.

The system operates based on the working principle of mechanical brake mechanism. The belt is attached to a lever and holds onto the roller with angle $\alpha$, the roller is connected to the wheel shaft via an elastic coupling. Tightening the belt by using a nut screw mounted on the lever, will increase friction resistance between the belt and the roller. An electronic scale is attached to the lever to collect the force displayed on the meter.

The equation for torque balance at point $\mathrm{M}$ can be described as follows: 

with a Drive System Integrated a CVT Transmission

$$
F_{m s} \cdot R+P_{1} \cdot L-P_{1} \cdot L+P . L=P . L
$$

where: $\mathrm{F}_{\mathrm{ms}}$ is the friction force between the roller and the belt; $\mathrm{R}$ is diameter of the roller; $\mathrm{P}$ is force displayed on the electronic scale.

The frictional moment of the wheel shaft is determined by the following expression:

$\mathrm{T}=\mathrm{P} . \mathrm{L}(\mathrm{N} \cdot \mathrm{m})$

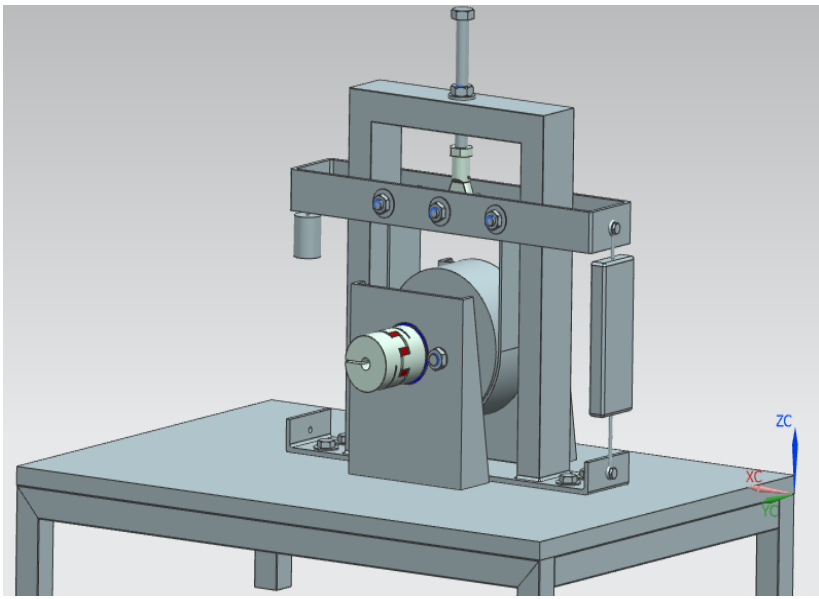

(a)

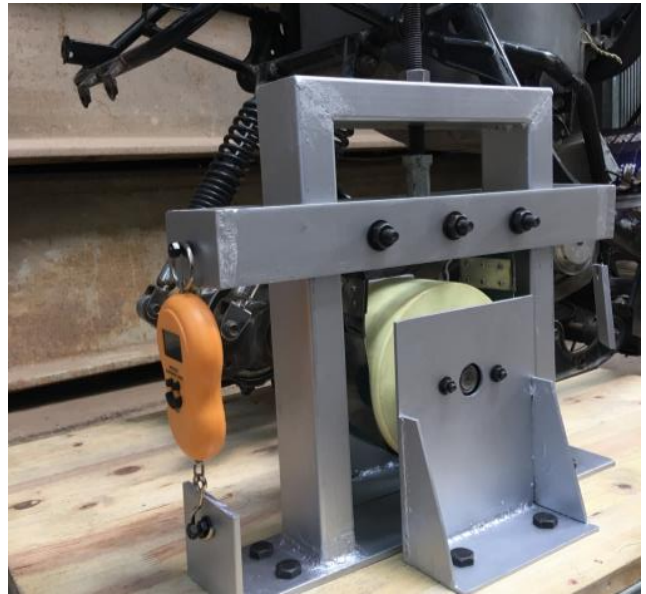

(b)

Figure 4: Torque Measurement Systems: (a) - Designed Model; (b) - Fabricated System.

The measuring system is placed on a table with dimensions of $800 \mathrm{~mm}$ x $600 \mathrm{~mm}$, which is made from wood with a shaped steel frame. The suspension system with dimensions of $355 \mathrm{~mm}$ x $260 \mathrm{~mm}$ is also made of steel box and mounted on the table by bolts. One lever with its size of $400 \mathrm{~mm}$ x $80 \mathrm{~mm}$ is suspended through the bearings with diameters of $\emptyset 15$ and bolts of M14. One side of the lever is attached with an electronic scale, the other is attached with counterbalance. The measurement system is described as in figure 4.

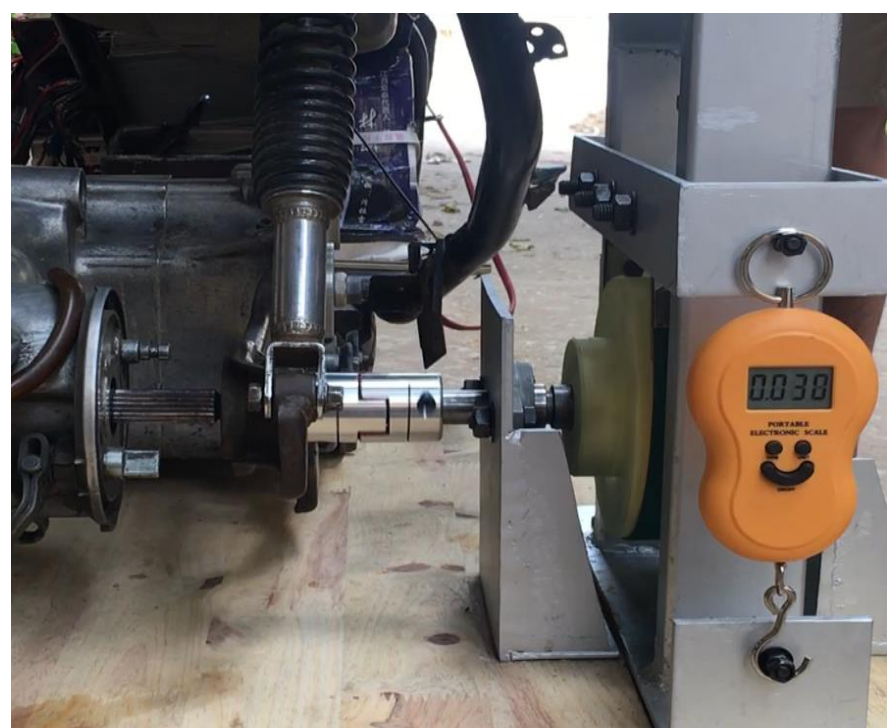

Figure 5: Torque Measurement System Connected with the Wheel Shaft.

The wheel shaft is attached to the measuring system via an elastic coupling, as described in figure 5. The system is adjusted to ensure the concentricity of the wheel axle and the bearings, ensuring accurate transmission without vibration. 
The experimental sequence is as follows: (1) adjust the balance system and adjust the indicator of the electronic scale to zero; (2) adjust the speed to be measured and increase the brake force until the wheel axle stops, collect the data; (3) repeat the measurement sequence at different speeds. The data obtained will be used to calculate the wheel shaft torque to evaluate the relation between the speeds and torque of the electric motorcycle.

\section{RESULTS AND DISCUSSIONS}

The wheel shaft torque of the electric motorcycle is calculated when considering the transmission efficiency of about $95 \%$. Accordingly, the torque value changes corresponding to the change of CVT ratio in the design range, this torque value depends on the wheel speed and is calculated according to the kinematic formula of the mechanical transmission, the results are shown in table 2 :

Table 2: Estimation of Wheel Shaft Torque of Electric Motorcycle

\begin{tabular}{|c|c|c|}
\hline No. & Wheel Shaft Speed (rpm) & Wheel Shaft Torque (N.m) \\
\hline 1 & 173.19 & 44.940 \\
\hline 2 & 259.79 & 29.959 \\
\hline 3 & 346.38 & 22.470 \\
\hline 4 & 432.98 & 17.976 \\
\hline 5 & 519.57 & 14.980 \\
\hline
\end{tabular}

The torque varies from the smallest value of 14.98 N.m when the vehicle reaches the maximum speed and increases gradually with smaller speeds. The torque reaches the value of 44.94 N.m when the wheel shaft speed is about $173 \mathrm{rpm}$. This ensures that the motorcycle is consistent with the urban traffic conditions, so that the wheel speed must change continuously, but the wheel torque remains at a value large enough to help the vehicle operating safely in these traffic conditions. The relationship between speed and wheel axle torque is shown in figure 6. It can be seen that the CVT ratio will automatically adjust when the vehicle is in traffic and ensure the torque helps the vehicle operate safely in the designed speed range, especially at low speeds.

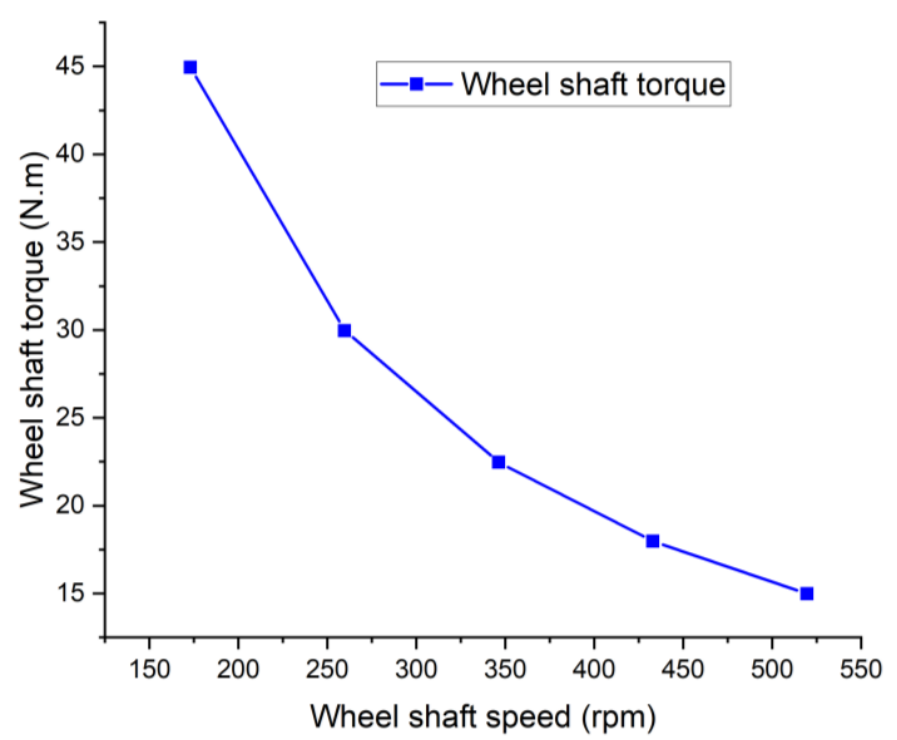

Figure 6: Estimation of Wheel Shaft Torque with Different Speeds. 

with a Drive System Integrated a CVT Transmission

To compare the calculated and measured results of wheel shaft torque, the torques were measured at the same speed range as mentioned above. Hence, the measurement system was set with five different speeds from $\mathrm{N}_{\min }$ of $173 \mathrm{rpm}$ to $\mathrm{N}_{\max }$ of $521 \mathrm{rpm}$ corresponding to the previous calculated values. Corresponding to each speed, the nut bolt was tightened until the roller stopped, the maximum force $\mathrm{P}$ at each different speed was collected. The measurement results are described in table 3. The relationship between the torque and wheel shaft speeds for both the calculation and measurement is shown in figure 7 .

Table 3: Measurement Results of Wheel Shaft Torque of Electric Motorcycle

\begin{tabular}{|c|c|c|c|}
\hline Wheel Shaft Speed (rpm) & Force P $(\mathbf{N})$ & $\mathbf{M}=$ P.L $(\mathbf{N} . \mathbf{m})$ & $\Delta \mathbf{M}(\%)$ \\
\hline 173 & 220.7 & 44.140 & 1.81 \\
\hline 260 & 167.8 & 33.560 & 10.73 \\
\hline 345 & 128.9 & 25.780 & 12.84 \\
\hline 435 & 96.3 & 19.260 & 6.67 \\
\hline 521 & 83.0 & 16.660 & 10.08 \\
\hline
\end{tabular}

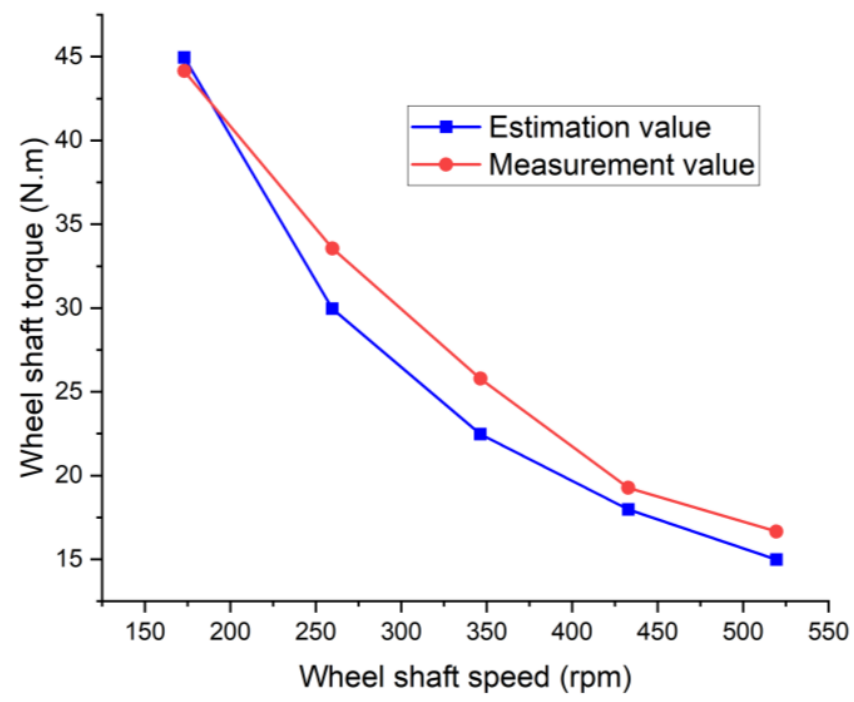

Figure 7: Wheel Shaft Torque Comparison between

Calculation and Measurement.

From the results in table 2, Table 3 and the graph in figure 7, it can be seen that there is a similarity between the measurement results and the calculated values. The wheel shaft torque decreases regularly from 44.14 N.m to 16.66 N.m as the speed increases from $173 \mathrm{rpm}$ to $521 \mathrm{rpm}$. The torque changes gradually, so there will be no jerky phenomenon when the vehicle changes its speed in the case of travelling in the urban traffic. Besides, when traveling at a small speed of 173 $\mathrm{rpm}$, the torque reaches a value of $44.14 \mathrm{Nm}$, which means that the torque is large enough when the vehicle changes from low speed to an accelerated state, ensuring a safe operation of the vehicle.

In addition, figure 7 shows that the difference in torque in the two cases of calculation and measurement varied from $1.8 \%$ to about $13 \%$. The difference is relatively uniform at speeds ranging from 260 to 520 rpm. The difference between the calculated and experimental values can be understood that because the calculations are not included all the 
factors affecting the mechanical properties of the vehicle. These deviations do not affect the purpose of the design and integration of the drive system with a CVT transmission, ensuring mechanical characteristics when participating in urban traffic conditions.

\section{CONCLUSIONS}

A measurement system was designed and manufactured determine the wheel shaft torque of an electric motorcycle with a drive system including a CVT transmission. The results show that the motorcycle operates stably with design parameters with the capable of operating at the maximum torque of 44.14 N.m at wheel speed of $173 \mathrm{rpm}$. At other speed ranges, the system automatically adjusts CVT ratios corresponding to those speeds, so that the wheel shaft torque will be suitable for the corresponding operating conditions, ensuring vehicle performance, avoiding slipping and jerking phenomenon when changing state from low speed to high speed. At higher speeds, the torque decreases, and the smallest value is about 16.6 N.m when the vehicle speed reaches its maximum value of $520 \mathrm{rpm}$. Besides, the test results also show that the vehicle operates safely in specific urban traffic conditions without jerk phenomenon when changing speed at the intersections or passing through the crowded places.

\section{ACKNOWLEDGEMENT}

This research is funded by the Hanoi University of Science and Technology (HUST) under project number T2018-TĐ-003.

\section{REFERENCES}

1. Y. Liu and I. Lai, The Effects of Environmental Policy and the Perception of Electric Motorcycles on the Acceptance of Electric Motorcycles: An Empirical Study in Macau, SAGE Open, vol. 10, no. 1, pp. 1-14, 01/01 2020, doi: 10.1177/2158244019899091.

2. P. Jeyapandiarajan, G. Kalaiarassan, J. Joel, R. Shirbhate, F. Felix Telare, and A. Bhagat, Design and Analysis of Chassis for an Electric Motorcycle, Mater. Today: Proc., vol. 5, no. 5, Part 2, pp. 13563-13573, 2018/01/01/ 2018, doi: https://doi.org/10.1016/j.matpr.2018.02.352.

3. Mavleev, I. R., I. I. Salakhov, and I. D. Valeev. "New hydro-mechanical continuously variable transmission." International Journal of Mechanical and Production Engineering Research and Development 8.S6 (2018): 1069-1076.

4. M. Hernandez, K. Kockelman, J. Lentz, and J. Lee, Emissions and noise mitigation through use of electric motorcycles, Transp. Safe. Env., vol. 1, pp. 164-175, 11/01 2019, doi: 10.1093/tse/tdz013.

5. M. Marinov, V. Valchev, R. Stoyanov, and P. Andreev, An Approach to the Electrical Sizing of The Electric Motorcycle Drive, in 20th International Symposium on Electrical Apparatus and Technologies (SIELA), 3-6 June 2018 2018, pp. 1-4, doi: 10.1109/SIELA.2018.8447065.

6. Sakat, Prasad, et al. "A Case Study on Response of Alloy Gear Steels to Case Carburizing and it's Effect on Weight Optimization of a Transmission System." International Journal of Mechanical and Production Engineering Research and Development (IJMPERD) 7.2, Apr 2017, 47-56

7. P. Y. Xuan, M. Henz, and J. D. Weigl, Environmental impact of converted electrical motorcycle, in World Electric Vehicle Symposium and Exhibition (EVS27), 17-20 Nov. 2013 2013, pp. 1-8, doi: 10.1109/EVS.2013.6914813.

8. Cogan, B. I. "Intelligent Automatic Software Engineering Tools For Software Analysis And Assessment." WIT Transactions on Information and Communication Technologies 14 (1970). 
9. D. G. Dorrell and M. Popescu, Drive motor designs for electric motorcycles, in IEEE Energy Conversion Congress and Exposition (ECCE), 15-20 Sept. 2012 2012, pp. 4354-4361, doi: 10.1109/ECCE.2012.6342230. [Online]. Available: https://ieeexplore.ieee.org/document/6342230/

10. S. Ruensumruay, W. Pattaraprakorn, V. Chutiprapat, and P. Bhasaputra, The study on the effect of electric motorcycle to energy consumption in Thailand, in 13th International Conference on Electrical Engineering/Electronics, Computer, Telecommunications and Information Technology (ECTI-CON), 28 June-1 July 2016 2016, pp. 1-4, doi: 10.1109/ECTICon.2016.7561407. [Online]. Available: https://ieeexplore.ieee.org/document/7561407/

11. Mehta, Dhruv, et al. "Automatic targeting system." International Journal of Electronics and Communication Engineering (IJECE), India (2013).

12. D. Tokunaga and K. Kesamaru, Development of novel PM motors for sport type electric motorcycles, in 15th International Conference on Electrical Machines and Systems (ICEMS), $21-24$ Oct. 2012 2012, pp. 1-4.

13. E. Fernandez and M. Coello, Comparative analysis of control techniques in drive systems for electric motorcycle, in 6th International Youth Conference on Energy (IYCE), 21-24 June 2017 2017, pp. 1-5, doi: 10.1109/IYCE.2017.8003710. [Online]. Available: https://ieeexplore.ieee.org/document/8003710/

14. P. E. Fernández and M. Coello, Implementation of electric motorcycle case of study: Cuenca-ecuador, in Congreso Internacional de Innovacion y Tendencias en Ingenieria (CONIITI), 4-6 Oct. 2017 2017, pp. 1-5, doi: 10.1109/CONIITI.2017.8273319.

15. J. Blissett, M. Degano, M. Gimeno-Fabra, and P. Wheeler, Design of electrical system for racing electric motorcycles, in International Conference on Electrical Systems for Aircraft, Railway, Ship Propulsion and Road Vehicles \& International Transportation Electrification Conference (ESARS-ITEC), 2-4 Nov. 2016 2016, pp. 1-5, doi: 10.1109/ESARSITEC.2016.7841419.

16. P. Wheeler, J. Blissett, and M. G. Fabra, Electric superbike racing - The design and construction of a championship winning electric superbike, in 7th International Conference on Power Electronics Systems and Applications - Smart Mobility, Power Transfer \& Security (PESA), 12-14 Dec. 2017 2017, pp. 1-5, doi: 10.1109/PESA.2017.8277747.

17. S. Matey, D. R. Prajapati, K. Shinde, A. Mhaske, and A. Prabhu, Design and fabrication of electric bike, Int. J. Mech. Eng. Technol., vol. 8, pp. 245-253, 03/01 2017.

18. T. Phan, T. Phan, and M. Tang, Solution of additional charging to electric motorcycles, Sci. J. Tra Vinh Uni., vol. 1, pp. 115119, 06/13 2019, doi: 10.35382/18594816.1.1.2019.97.

19. A. Siriwattanapong and C. Chantharasenawong, Electric motorcycle charging station powered by solar energy, IOP Conf. Ser.: Mater. Sci. Eng., vol. 297, p. 012060, 2018/01 2018, doi: 10.1088/1757-899x/297/1/012060.

20. M. Cengiz and M. Mamis, Use of Solar Energy in Electric Vehicles, Int. J. Eng. Technol., vol. 1, p. 123, 12/23 2015, doi: 10.19072/ijet.90265.

21. M. Saadatmandi and S. Hakimi, "Optimal Utilization of Solar Energy for Electric Vehicles Charging in a Typical Microgrid," in Electric Vehicles in Energy Systems: Springer, Cham, 2020, pp. 129-164.

22. M. Waseem, A. Sherwani, and M. Suhaib, Integration of solar energy in electrical, hybrid, autonomous vehicles: a technological review, SN Appl. Sci., vol. 1, p. 1459, 10/01 2019, doi: 10.1007/s42452-019-1458-4.

23. F. Ibanez, A. Florez, S. Gutiérrez, and J. Echeverria, Extending the Autonomy of a Battery for Electric Motorcycles, IEEE Trans. Veh. Technol., vol. PP, pp. 1-1, 02/01 2019, doi: 10.1109/TVT.2019.2896901. 
24. L. Cheng, X. Yi, B. H. Min, and K. Haran, Ring Motor Front Wheel for Electric Motorcycle, in IEEE Power and Energy Conference at Illinois (PECI), 28 Feb.-1 March 2019 2019, pp. 1-8, doi: 10.1109/PECI.2019.8698911. 